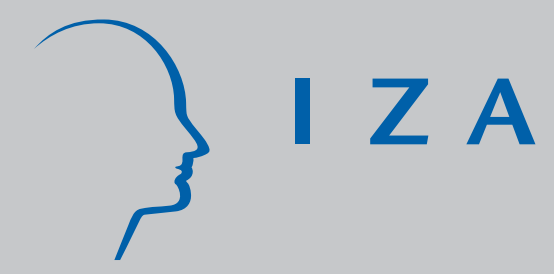

IZA DP No. 2401

Multi-Levels Bargaining and Efficiency in Search Economies

Olivier L'Haridon

Franck Malherbet

October 2006 


\title{
Multi-Levels Bargaining and Efficiency in Search Economies
}

\author{
Olivier L'Haridon \\ GRID, CNRS, ENSAM \\ Franck Malherbet \\ THEMA, CNRS, Université de Cergy-Pontoise, \\ fRDB and IZA Bonn
}

\section{Discussion Paper No. 2401 \\ October 2006}

\author{
IZA \\ P.O. Box 7240 \\ 53072 Bonn \\ Germany \\ Phone: +49-228-3894-0 \\ Fax: +49-228-3894-180 \\ Email: iza@iza.org
}

\begin{abstract}
Any opinions expressed here are those of the author(s) and not those of the institute. Research disseminated by IZA may include views on policy, but the institute itself takes no institutional policy positions.

The Institute for the Study of Labor (IZA) in Bonn is a local and virtual international research center and a place of communication between science, politics and business. IZA is an independent nonprofit company supported by Deutsche Post World Net. The center is associated with the University of Bonn and offers a stimulating research environment through its research networks, research support, and visitors and doctoral programs. IZA engages in (i) original and internationally competitive research in all fields of labor economics, (ii) development of policy concepts, and (iii) dissemination of research results and concepts to the interested public.
\end{abstract}

IZA Discussion Papers often represent preliminary work and are circulated to encourage discussion. Citation of such a paper should account for its provisional character. A revised version may be available directly from the author. 
IZA Discussion Paper No. 2401

October 2006

\section{ABSTRACT}

\section{Multi-Levels Bargaining and Efficiency in Search Economies}

In this note, we extend the traditional search and matching framework to take account of the different levels at which negotiations take place. We show that, in the absence of any distortion, sector-level bargaining ought to be less efficient than bargaining taking place at the other levels. It follows that the introduction of labor market policies as a combination of employment protection, hiring subsidy and payroll tax improves efficiency. This result suggests that the relationship between the level at which bargaining takes place and the labor market performance is far more conditional than most studies acknowledge.

JEL Classification: J51, J60

Keywords: search and matching models, bargaining levels, labor market policies

Corresponding author:

Franck Malherbet

Université de Cergy-Pontoise

THEMA

33, boulevard du port

95011 Cergy-Pontoise cedex

France

E-mail: franck.malherbet@u-cergy.fr 


\section{Introduction}

The question of labor market flexibility and the role played by institutions - with a particular emphasis on employment protection - has attracted a lot of attention in the last decade. The Mortensen-Pissarides search and matching framework has become the standard equilibrium unemployment theory to study labor market dynamics (Rogerson, Shimer and Wright, 2005). In this theoretical note, we extend the Mortensen-Pissarides framework to take account of a salient feature of European countries, namely the level at which negotiations are conducted. We show that in the absence of any distortion, sector-level bargaining ought to be less efficient than bargaining taking place at the other levels. As a consequence there is an explicit justification for the introduction of labor market policies in our framework. We show that a proper combination of employment protection, hiring subsidy and payroll tax allows to correct the inefficiency generated by sector-level bargaining. This result suggests that the relationship between the level at which bargaining takes place and the labor market performance is far more conditional than most studies acknowledge.

\section{The model}

Economic environment: Contrary to the conventional search and matching framework, we assume the economy is made up of $J$ sectors or industries indexed by the subscript $j=1 \ldots J^{1}$. Each sector produces a different good in quantity $y_{j}$. All agents discount future payoffs at rate, $r>0$, and are risk neutral. There is a continuum of small firms in perfect competition, the number of which is endogenous in equilibrium. Under the small firm hypothesis, firms have a single job slot and either produce with one worker, or search with an open vacancy. In case of vacancy, the firm has to pay a search flow cost $\gamma>0$ per unit of time. Each job is endowed with an irreversible production technology requiring one unit of labor to produce $\varepsilon$ units of output. Upon meeting a common start-up productivity level $\varepsilon_{u}$ is assumed for all job-worker matches. On every continuing job, productivity changes according to an idiosyncratic stochastic process, which is Poisson with arrival rate $\lambda$. When a shock supervenes, a new value of the job specific productivity is drawn from a $\operatorname{CDF} G($.$) with support over the range \left[\varepsilon_{l}, \varepsilon_{u}\right]$. There is an endogenous threshold value of the productivity, denoted by $\varepsilon_{d_{j}}$, below which the match is destroyed. Thus the rate at which existing jobs are destroyed follows a Poisson process with parameter $\lambda G\left(\varepsilon_{d_{j}}\right)$.

The labor market is populated by a measure one of infinitely lived workers. Each worker supplies one unit of labor and can be either employed and producing or unemployed and searching. We assume that the aggregate consumption $c_{i}$ of agent $i$ is a CES type function of the different goods $j$ produced in the economy. Put differently, $c_{i}$ represents a composite good which price is normalized to unity. Formally, the instantaneous utility of agent $i$ verifies $\phi\left(c_{i}\right)=c_{i}=J^{\frac{1}{1-\sigma}}\left[\sum_{j=1}^{J} c_{j i}^{\frac{\sigma-1}{\sigma}}\right]^{\frac{\sigma}{\sigma-1}}$, where $\sigma>1$ is the elasticity of substitution among goods.

Search on the labor market: The labor market is perfectly segmented. We assume that there is no labor mobility between industries and that unemployed workers search onto an unique sector ${ }^{2}$. In each sector $j$, matching is frictional and is captured by a function $m\left(v_{j}, u_{j}\right)$

\footnotetext{
${ }^{1}$ For the remainder of the paper, a variable indexed with the letter $j$ refers to the sector $j$. For instance $\theta_{j}$ and $\varepsilon_{d_{j}}$ denote the labor market tightness and the reservation productivity in sector $j$ respectively.

${ }^{2}$ This assumption is justified on the ground that inter-sector reallocations are a small component of overall job reallocations (Davis and Haltiwanger, 1999).
} 
where $v_{j}$ and $u_{j}$ stand for the total mass of unemployed workers and the total mass of vacancies respectively. This matching function is assumed increasing in both its arguments, concave and homogeneous of degree one. Let $\theta_{j}=v_{j} / u_{j}$ denote the labor market tightness. The linear homogeneity of the matching function allows to write the rate at which vacant jobs are filled as $m\left(v_{j}, u_{j}\right) / v_{j}=m\left(1, u_{j} / v_{j}\right)=m\left(\theta_{j}\right)$ and the rate at which unemployed workers find a job as $m\left(v_{j}, u_{j}\right) / u_{j}=\theta_{j} m\left(\theta_{j}\right)$. It is straightforward to verify that $m\left(\theta_{j}\right)$ and $\theta_{j} m\left(\theta_{j}\right)$ are decreasing and increasing in the labor market tightness respectively.

Unemployment and Production Flows: Assuming that only the unemployed workers search for a job, the motion's laws for unemployment and production are given by the following two conventional equations:

$$
\begin{gathered}
\dot{u}_{j}=\lambda G\left(\varepsilon_{d_{j}}\right)\left(1-u_{j}\right)-\theta_{j} m\left(\theta_{j}\right) u_{j} \\
\dot{y}_{j}=\theta_{j} m\left(\theta_{j}\right) u_{j} \varepsilon_{u}+\lambda\left(1-u_{j}\right) \int_{\varepsilon_{d_{j}}}^{\varepsilon_{u}} \zeta d G(\zeta)-\lambda y_{j}
\end{gathered}
$$

The labor market in each sector is in equilibrium when the stock-flow condition for constant unemployment holds. It follows that the equilibrium unemployment rate in sector $j$ reads:

$$
u_{j}=\frac{\lambda G\left(\varepsilon_{d_{j}}\right)}{\theta_{j} m\left(\theta_{j}\right)+\lambda G\left(\varepsilon_{d_{j}}\right)}
$$

\section{Labor Market Equilibria and Properties}

In order to compare the properties of the different bargaining setups, we distinguish between three levels of negotiation; (i) a completely decentralized bargaining level; (ii) an intermediate sector bargaining level; and finally (iii) a completely centralized bargaining level.

\section{Decentralized Bargaining}

In this case, the bargaining involves a single worker and a single firm. There is no coordination between agents and the relative prices, $p_{j}$, are thus considered as given. Following the bulk of the search and matching literature, the wage is determined according to a generalized Nash criterion and the model boils down to the two traditional job creation and job destruction conditions (see Pissarides (2000), chapter 2, for details):

$$
\begin{gathered}
\frac{\gamma}{m\left(\theta_{j}\right)}=[1-\beta]\left(\frac{\varepsilon_{u}-\varepsilon_{d_{j}}}{r+\lambda}\right) p_{j}, \\
p_{j} \varepsilon_{d_{j}}=z+\frac{\beta}{1-\beta} \theta_{j} \gamma-p_{j} \frac{\lambda}{r+\lambda} \int_{\varepsilon_{d_{j}}}^{\varepsilon_{u}}\left(\zeta-\varepsilon_{d_{j}}\right) d G(\zeta),
\end{gathered}
$$

where $\beta$ stands for the bargaining power of the worker. Finally, at the symmetric Nash equilibrium all sectors are ex-post identical and the relative prices are equal to unity for all sectors.

\section{Sector Level Bargaining}

In this case, following Cahuc and Zylberberg (2004), we assume that the agents are able of coordinating their actions in order to draw up efficient contracts that maximize the net output of the sector. Put differently, in each sector the workers and the firms commit themselves to maximize the net surplus of the sector taking account of the motion's laws of both unemployment and production and considering the actions of the agents in the other sectors as given. Once 
maximized, the net surplus is split between the firms and the workers thanks to lump-sum transfers. The net instantaneous output in sector $j$ is the real value of production minus the vacancy costs. The program of the coalition reads:

$$
\underset{\theta_{j}, \varepsilon_{d_{j}}}{\operatorname{Max}} \Omega_{j}=\int_{0}^{\infty} e^{-r t}\left(p_{j} y_{j}+u_{j} z-\theta_{j} u_{j} \gamma\right) d t,
$$

subject to (1) and (2). After a few algebra, the equilibrium values of the productivity threshold $\varepsilon_{d_{j}}$ and the labor market tightness $\theta_{j}$ comes down to:

$$
\begin{gathered}
\frac{\gamma}{m\left(\theta_{j}\right)}=\left[1-\eta\left(\theta_{j}\right)\right]\left(\frac{\varepsilon_{u}-\varepsilon_{d_{j}}}{r+\lambda}\right) p_{j} \frac{\sigma-1}{\sigma}, \\
p_{j} \varepsilon_{d_{j}}=\frac{\sigma}{\sigma-1}\left(z+\frac{\eta\left(\theta_{j}\right)}{1-\eta\left(\theta_{j}\right)} \theta_{j} \gamma\right)-p_{j} \frac{\lambda}{r+\lambda} \int_{\varepsilon_{d_{j}}}^{\varepsilon_{u}}\left(\zeta-\varepsilon_{d_{j}}\right) d G(\zeta),
\end{gathered}
$$

where $\eta\left(\theta_{j}\right)$ is the elasticity of the matching function with respect to unemployment. Finally, at the symmetric Nash equilibrium the sectors are all alike and the relative prices are equal to unity, hence $p_{j}=1, \forall j=1 \ldots J$.

\section{Centralized Bargaining}

In this case, all the agents in all the sectors coordinate each other so as to maximize the net surplus of the economy. All sectors being identical, it is possible to straight off set $p_{j}$ equal to one. Taking account of this fact, the problem of the centralized coalition is almost similar to the previous case. Hence maximization of (4) with $p_{j}=1$ subject to (1) and (2) yields:

$$
\begin{gathered}
\frac{\gamma}{m\left(\theta_{j}\right)}=\left[1-\eta\left(\theta_{j}\right)\right]\left(\frac{\varepsilon_{u}-\varepsilon_{d_{j}}}{r+\lambda}\right), \\
\varepsilon_{d_{j}}=z+\frac{\eta\left(\theta_{j}\right)}{1-\eta\left(\theta_{j}\right)} \theta_{j} \gamma-\frac{\lambda}{r+\lambda} \int_{\varepsilon_{d_{j}}}^{\varepsilon_{u}}\left(\zeta-\varepsilon_{d_{j}}\right) d G(\zeta) .
\end{gathered}
$$

The three sets of job creation and job destruction conditions defined above determine three different labor market outcomes. Remarking that the centralized case is by nature efficient (Pissarides, 2000), it seems natural to use it as a benchmark. The following properties shed light on the connection between the different cases.

Proposition 3.1 A decentralized equilibrium is efficient if, and only if, the share of labor, $\beta)$, is equal to the elasticity of job matching with respect to unemployment, $\eta($.$) . This is the$ conventional Diamond-Hosios-Pissarides condition.

Proof : Straightforward by comparing the job creation conditions $(J C D)$ and $\left(J C^{*}\right)$ and the job destruction conditions $(J D D)$ and $\left(J D^{*}\right)$ with $\beta=\eta\left(\theta_{j}\right)$ at the symmetric Nash equilibrium. There is thus an unique share of the surplus that makes firms open and close the efficient number of jobs.

Corollary : Distant from this condition, a decentralized equilibrium is not efficient. Job creation can be either above the efficient level (if $\beta<\eta($.$) ) or below the efficient level (if \beta>\eta($.$) )$ and job destruction is always too low. There is therefore no explicit justification for employment protection in such an equilibrium. However, in an economy composed of several sectors producing different goods, the labor market equilibrium conditions differ from the baseline decentralized case. 
Proposition 3.2 A sector level equilibrium is efficient if, and only if, the elasticity of substitution among goods, $\sigma$, goes to infinity.

Proof : Straightforward by comparing the job creation conditions $(J C S)$ and $\left(J C^{*}\right)$ and the job destruction conditions $(J D S)$ and $\left(J D^{*}\right)$ with $\sigma \rightarrow \infty$ at the symmetric Nash equilibrium. Since the elasticity among goods is infinite, the economy boils down to the conventional single sector case.

Nevertheless, goods are certainly different among sectors, hence leading to different labor market outcomes. The next two propositions shed light on the effect of $\sigma$ on the job creation, the job destruction and consequently on the equilibrium unemployment rate.

Proposition 3.3 The labor market tightness is increasing in the elasticity of substitution among goods, $\sigma$. An economy with a high level of product differentiation entails a lower level of job creations than an economy with a low level of product differentiation or obviously than an efficient decentralized economy.

Proof : See Appendix.

It is straightforward according to proposition 3.3 to remark that as soon as $\sigma$ is finite job creation is inefficient and the unemployment spells are thus longer the lower $\sigma$. More accurately, the monopoly power of each sector is all the more important that $\sigma$ is low, hence leading firms to reduce production and to open less vacancies. All other things being equal (for a given destruction rate) the equilibrium unemployment rate is thus higher the lower $\sigma$. Things appear less clear-cut with regard to the job destruction as stated by proposition 3.4.

Proposition 3.4 The reservation productivity is a non-monotonic function of the elasticity of substitution among goods, $\sigma$ :

- if $v_{j} \gamma / u_{j} z>1$, the reservation productivity increases in the elasticity of substitution $\sigma$.

- if $v_{j} \gamma / u_{j} z<1$, the reservation productivity decreases in the elasticity of substitution $\sigma$.

Proof : See Appendix.

An increase in $\sigma$ has two effects on the job destruction condition $(J D S)$. First, it reduces the weight of the employment's opportunity cost and consequently decreases the reservation's productivity for a given labor market tightness. Labor hoarding is thus increased. Second, as the labor market tightness is increasing in $\sigma$, the employment's opportunity cost is in turn increased as well as the reservations productivity. Labor hoarding is thus decreased. Accordingly, the overall effect on job destruction appears ambiguous, hence the effect on the equilibrium unemployment rate.

It is worth remarking that when the condition $v_{j} \gamma / u_{j} z<1$ holds the economy is characterized by both an inefficiently high job destruction rate and unemployment rate. As a matter of fact, in such a case the level of protection supplied by the monopoly power reduces the cost of job destruction leading to inefficient separations which are not compensated by higher job creations. The first best solution therefore consists in increasing competition among sectors so as to reach an efficient equilibrium. Still, in our framework the monopoly power originates from consumers' demand behavior rather than from firms' behavior. In such a case, labor market policies appear therefore a natural means to correct for sector-level bargaining inefficiencies. 


\section{Labor market policies and efficiency}

In this section, we investigate the ability of labor market policies to correct for the distortion induced by the bargaining at the sector-level. Three policy instruments are considered: (i) a payroll tax $(\tau)$, (ii) a hiring subsidy $(H)$ and (iii) a firing cost $(F)$. For a given sector, the net instantaneous production is now made up of the positive and negative transfers associated with labor market policies which consist in the subsidies given to the firms for the $\theta_{j} m\left(\theta_{j}\right) u_{j}$ new matches, the firing costs paid by the firms for the $\left(1-u_{j}\right) \lambda G\left(\varepsilon_{d_{j}}\right)$ jobs destroyed, and the taxes charged on the $\left(1-u_{j}\right)$ productive job-worker matches. Furthermore, and to avoid any additional distortion, firms are granted a transfer equal to $\left(1-u_{j}\right) r H$ which is meant to take account of the welfare loss associated with the implementation of labor market policies. It follows that the maximisation problem faced by a given sector writes:

$$
\underset{\varepsilon_{d j}, \theta_{j}}{\operatorname{Max}} \Omega_{j}=\int_{0}^{\infty} e^{-r t}\left[\begin{array}{c}
p_{j} y_{j}+u_{j} z-\theta_{j} u_{j} \gamma+\theta_{j} m\left(\theta_{j}\right) u_{j} H+\left(1-u_{j}\right) r H \\
-\left(1-u_{j}\right) \tau-\left(1-u_{j}\right) \lambda G\left(\varepsilon_{d_{j}}\right) F
\end{array}\right] d t,
$$

subject to (1) and (2). After a few algebra this program entails:

$$
\begin{gathered}
\frac{\gamma}{m\left(\theta_{j}\right)}=\left[1-\eta\left(\theta_{j}\right)\right]\left(\frac{\varepsilon_{u}-\varepsilon_{d_{j}}}{r+\lambda} p_{j} \frac{\sigma-1}{\sigma}+H-F\right) \\
p_{j} \varepsilon_{d_{j}}=\frac{\sigma}{\sigma-1}\left[z+\tau+\frac{\eta\left(\theta_{j}\right)}{1-\eta\left(\theta_{j}\right)} \theta_{j} \gamma-r(H+F)\right]-p_{j} \frac{\lambda}{r+\lambda} \int_{\varepsilon_{d_{j}}}^{\varepsilon_{u}}\left(\zeta-\varepsilon_{d_{j}}\right) d G(\zeta) .
\end{gathered}
$$

Finally at the symmetric Nash equilibrium all sectors are ex-post similar and the relative prices are equal to unity. The efficient economic policy consists in finding the triplet $(\tau, H, F)$ that allows the sector-level equilibrium defined by $(6)$ and (7) to reach the efficient decentralized equilibrium or alternatively the optimum defined by $\left(J C^{*}\right)$ and $\left(J D^{*}\right)$. By identification of equations (6) and $\left(J C^{*}\right)$ on one hand, and $(7)$ and $\left(J D^{*}\right)$ on the other hand, it is straightforward to obtain the efficient values of $H$ and $F$. It follows ${ }^{3}$ :

$$
\begin{gathered}
H=F+\frac{1}{\sigma}\left(\frac{\varepsilon_{u}-\varepsilon_{d_{j}}^{*}}{r+\lambda}\right) . \\
r F=\tau-r H+\frac{1}{\sigma}\left(z+\frac{\eta\left(\theta_{j}^{*}\right)}{1-\eta\left(\theta_{j}^{*}\right)} \theta_{j}^{*} \gamma\right) .
\end{gathered}
$$

Assuming a balanced budget constraint, the lump-sum payroll tax solves at the symmetric Nash equilibrium:

$$
\theta_{j}^{*} m\left(\theta_{j}^{*}\right) u_{j}^{*} H+\left(1-u_{j}^{*}\right) r H=\left(1-u_{j}^{*}\right) \tau+\left(1-u_{j}^{*}\right) \lambda G\left(\varepsilon_{d_{j}}^{*}\right) F .
$$

Finally, the system made up of equations (8), (9) and (10) permits to define the set of policies that yields an efficient labor market equilibrium. The firing tax solves:

$$
r F=\underbrace{\frac{1}{\sigma} \lambda G\left(\varepsilon_{d_{j}}^{*}\right)\left(\frac{\varepsilon_{u}-\varepsilon_{d_{j}}^{*}}{r+\lambda}\right)}_{\text {Fiscal Distortion }}+\underbrace{\frac{1}{\sigma}\left(z+\frac{\eta\left(\theta_{j}^{*}\right)}{1-\eta\left(\theta_{j}^{*}\right)} \theta_{j}^{*} \gamma\right)}_{\text {Monopoly Power Distortion }} .
$$

Firing costs correct for the excess job destruction induced by the taxation and the monopoly power. They are made up of two components: The first term on the RHS gives the amount of

\footnotetext{
${ }^{3}$ The star power index denotes the efficient value of the endogenous variables.
} 
employment protection required to compensate for the increase in the reservation's productivity induced by the lump-sum payroll tax. The second term represents the amount of job protection necessary to correct for the distortion induced by the sector's monopoly power. One should however remark that the dismissal costs cannot be implemented alone due to the fact they also decrease job creations. As pointed out by Pissarides (2000), a hiring subsidy must be introduced to correct for the fall in job creation. The hiring subsidy reads:

$$
r H=r F+\frac{r}{\sigma}\left(\frac{\varepsilon_{u}-\varepsilon_{d_{j}}^{*}}{r+\lambda}\right)
$$

It compensates for the loss in job creations induced, in the first place, by the dismissal costs captured by the first term of (12) - , and in the second place, by the restriction in the production due to the monopoly power - captured by the second term of (12)—. Finally, using (10) together with (11) and (12), the lump-sum payroll tax on productive matches writes:

$$
\tau=\frac{2 r+\lambda G\left(\varepsilon_{d_{j}}^{*}\right)}{\sigma}\left(\frac{\varepsilon_{u}-\varepsilon_{d_{j}}^{*}}{r+\lambda}\right)+\frac{1}{\sigma}\left(z+\frac{\eta\left(\theta_{j}^{*}\right)}{1-\eta\left(\theta_{j}^{*}\right)} \theta_{j}^{*} \gamma\right)
$$

Proposition 4.1 For any sector-level bargaining, there is an optimal labor market policies vector $(\tau, H, F)$ defined by equations (11), (12) and (13) that ensures the efficiency of the negotiation at the sector-level. Hence, these complementarities advocate for a labor market policies design contingent upon the bargaining level.

\section{Conclusion}

In this note, we have extended the traditional search and matching framework to take account of the different levels at which negotiations take place. It has been shown that absent from any distortion sector-level bargaining ought to be less efficient than bargaining taking place at the other levels. The introduction of labor market policies leads us to argue that a proper combination of employment protection, hiring subsidy and payroll tax improves labor market efficiency. From this standpoint, it is therefore worth noting that the relationship between the level at which bargaining takes place and the labor market performance is far more conditional than most studies acknowledge and is contingent upon the labor market institutions as recently conjured up by Flanagan (1999) or Cahuc and Zylberberg (2004). Hence, our results suggest to embed labor market institutions into the analysis in order to evaluate the relationship between the labor market performance and the level at which negotiations are conducted.

\section{References}

[1] Cahuc, P. and Zylberberg, A., (2004), Labor Economics, Cambridge : MIT Press.

[2] Davis, S. and Haltiwanger, J., (1999), "Gross job flows" in Ashenfelter, O. et Card, D. (eds), Handbook of Labor Economics, volume 3B, chapter 41, Amsterdam : North Holland.

[3] Flanagan, R. (1999), "Macroeconomic Performance and Collective Bargaining: An International Perspective", Journal of Economic Literature, 37, pp. 1150-1175.

[4] Rogerson R., Shimer R. and Wright R. (2005), "Search Theoretic Models of the Labor Market", Journal of Economic Literature, 43, pp. 959-988.

[5] Pissarides, C. (2000), Equilibrium Unemployment Theory, Cambridge MA: MIT Press. 


\section{Appendix}

Comparative Static : Assuming the matching function is of the Cobb-Douglas form, differentiation of $(J C S)$ and $(J D S)$ with respect to $\theta_{j}, \varepsilon_{d_{j}}$ and $\sigma$ yields at the symmetric Nash equilibrium:

$$
\begin{gathered}
-\frac{m^{\prime}\left(\theta_{j}\right)}{m\left(\theta_{j}\right)} \frac{\gamma}{m\left(\theta_{j}\right)} d \theta_{j}=-\frac{1-\eta}{r+\lambda} \frac{\sigma-1}{\sigma} d \varepsilon_{d_{j}}+(1-\eta)\left(\frac{\varepsilon_{u}-\varepsilon_{d_{j}}}{r+\lambda}\right) \frac{d \sigma}{\sigma^{2}}, \\
d \varepsilon_{d_{j}}=\frac{\sigma}{\sigma-1} \frac{\eta}{1-\eta} \gamma d \theta_{j}-\left(z+\frac{\eta}{1-\eta} \theta_{j} \gamma\right) \frac{d \sigma}{(\sigma-1)^{2}}+\frac{\lambda\left(1-G\left(\varepsilon_{d_{j}}\right)\right)}{r+\lambda} d \varepsilon_{d_{j}} .
\end{gathered}
$$

Let $\mathbf{J}$ be the jacobian matrix of the system made up of equations (A-1) and (A-2). The matrix reads: $\mathbf{J}=\left[\begin{array}{cc}\frac{r+\lambda G\left(\varepsilon_{d_{j}}\right)}{r+\lambda} & -\frac{\sigma}{\sigma-1} \frac{\eta}{1-\eta} \gamma \\ \frac{1-\eta}{r+\lambda} \frac{\sigma-1}{\sigma} & \frac{\gamma \eta}{\theta_{j} m\left(\theta_{j}\right)}\end{array}\right]$ with $\operatorname{det} \mathbf{J}>0$. Solving for $\frac{d \varepsilon_{d_{j}}}{d \sigma}$ and $\frac{d \theta_{j}}{d \sigma}$ yields:

$$
\begin{aligned}
\frac{d \varepsilon_{d_{j}}}{d \sigma} & =\frac{1}{\operatorname{det} \mathbf{J}}\left(\frac{\gamma}{(\sigma-1)^{2} m\left(\theta_{j}\right)}\right)\left(v_{j} \gamma-u_{j} z\right) \\
\frac{d \theta_{j}}{d \sigma} & =\frac{1}{\operatorname{det} \mathbf{J}}\left(\frac{1}{(r+\lambda) \sigma(\sigma-1)}\right)\left(\frac{\gamma r+\gamma \lambda G\left(\varepsilon_{d_{j}}\right)}{m\left(\theta_{j}\right)}+(1-\eta) z+\eta \theta_{j} \gamma\right)
\end{aligned}
$$

Proof of proposition 3: From (A-4) and knowing that $\eta \in[0 ; 1]$ and $\operatorname{det} \mathbf{J}>0$, it is straightforward to show that:

$$
\frac{d \theta_{j}}{d \sigma}>0
$$

Hence the labor market tightness, $\theta_{j}$, is increasing in the elasticity of substitution among goods.

Proof of proposition 4: From (A-3) and knowing that $\operatorname{det} \mathbf{J}>0$, the sign of $\frac{d \varepsilon_{d_{j}}}{d \sigma}$ satisfies:

$$
\operatorname{sgn}\left(\frac{d \varepsilon_{d_{j}}}{d \sigma}\right)=\operatorname{sgn}\left(v_{j} \gamma-u_{j} z\right)
$$

Finally, dividing $v_{j} \gamma-u_{j} z$ by $u_{j} z$, the sign of $\frac{d \varepsilon_{d_{j}}}{d \sigma}$ becomes conditional on $v_{j} \gamma / u_{j} z$. Hence:

- If $v_{j} \gamma / u_{j} z>1$ then $\frac{d \varepsilon_{d_{j}}}{d \sigma}>0$,

- If $v_{j} \gamma / u_{j} z<1$ then $\frac{d \varepsilon_{d_{j}}}{d \sigma}<0$. 